\title{
The Feasibility of Tracheal Oxygen Supplementation during Flexible Bronchoscopy
}

\author{
Jonas Yserbyt ${ }^{a} \quad$ Nikolaas De Maeyer ${ }^{a} \quad$ Christophe Dooms $^{a}$ Dries Testelmans ${ }^{a}$ \\ Inge Muylle ${ }^{b} \quad$ Marie Bruyneel $^{b}$ Vincent Ninane ${ }^{b}$ \\ ${ }^{a}$ Department of Respiratory Diseases, University Hospitals Leuven, Leuven, and bepartment of Pneumology, \\ Saint-Pierre University Hospital, Brussels, Belgium
}

\section{Key Words}

Hypoxemia · Bronchoscopy · Oxygen delivery

\begin{abstract}
Background: Hypoxemia is a frequent adverse event occurring during flexible bronchoscopy and is usually prevented by close monitoring and, if needed, oxygen supplementation by nasal cannula. Objective: We aim to demonstrate that tracheal oxygen supplementation during flexible bronchoscopy is a feasible, safe and effective method to restore oxygen saturation levels after oxygen desaturation. Methods: In a first phase, we compare oxygen supplementation by the tracheal or nasal route in a single blinded cross-over design in healthy volunteers. In a second phase, we study patients referred for diagnostic flexible bronchoscopy, who desaturate despite oxygen supplementation by nasal cannula, in order to assess the ability to correct hypoxemia through tracheal oxygen supplementation. Results: In the first phase, the mean capillary partial pressure of oxygen was $181 \mathrm{~mm} \mathrm{Hg}$ when oxygen at a flow rate of 4 liters/min was administered by the tracheal route, compared to $125 \mathrm{~mm} \mathrm{Hg}$ by the nasal route $(p<0.001)$. The capillary partial pressure of carbon dioxide was not significantly different. During 950 bronchoscopic procedures in the second phase of the trial,
\end{abstract}

30 patients desaturated below $90 \%$ despite oxygen supplementation by nasal cannula. In 22 out of these 30 patients, switching to the tracheal route resulted in a correction of the saturation within $120 \mathrm{~s}$. In the remaining 8 patients, saturation levels were corrected after increasing the oxygen flow rate to 4 liters $/ \mathrm{min}$. After restoring saturation levels, the bronchoscopy could be completed in 25 of 30 patients. Conclusions: Tracheal oxygen supplementation is safe, feasible and an effective way to restore oxygen saturation levels during flexible bronchoscopy.

(c) 2016 S. Karger AG, Basel

\section{Introduction}

Flexible bronchoscopy is a widely used and accepted technique, serving different diagnostic and therapeutic purposes. Although flexible bronchoscopy is regarded as a noninvasive method, many patients experience discomfort during the procedure, which may be partly related to hypoxemia. Without nasal oxygen supplementation during flexible bronchoscopy, about $35 \%$ of the patients experience hypoxemia, defined as peripheral transcutaneous oxygen saturation $\left(\mathrm{SpO}_{2}\right)$ below 85\% [1]. With 4 liters/min nasal oxygen supplementation, 3 versus $30 \%$ of

\section{KARGER}

E-Mail karger@karger.com www.karger.com/res
C 2016 S. Karger AG, Basel

0025-7931/16/0921-0048\$39.50/0
Jonas Yserbyt

Department of Respiratory Diseases

University Hospitals KU Leuven

Herestraat 49, BE-3000 Leuven (Belgium)

E-Mail jonas.yserbyt@uzleuven.be 
the patients experience $\mathrm{SpO}_{2}$ values below $90 \%$ after midazolam versus propofol bolus administration, respectively $[2,3]$. Moreover, hypoxemia can lead to serious adverse events, including cardiac arrhythmia, coronary insufficiency, neurologic complications and acute respiratory insufficiency [4].

Therefore, current guidelines on flexible bronchoscopy recommend monitoring of peripheral oxygen saturation by pulse oximetry and even cardiac monitoring in selected patients [5]. Oxygen saturation should not drop below $90 \%$, and desaturation is usually prevented by nasal oxygen delivery at a flow rate of 2-4 liters/min. Despite this precaution, hypoxemia still occurs due to the fact that delivery through a nasal cannula shows flow limitations and nose breathing is often less coordinated during bronchoscopy (e.g., as a result of agitation). Recent data show that the respiratory rate, minute-volume and mouth position significantly influence the inspired oxygen concentration [6].

Oxygen supplementation might be improved during flexible bronchoscopy when administered directly within the trachea. This hypothesis is supported by data from trials studying the use of long-term transtracheal oxygen therapy, showing its potential benefits over nasal oxygen delivery such as correction of hypoxemia unresponsive to nasal oxygen supplementation and a reduction of the flow rate of oxygen supplementation when delivered through a transtracheal catheter as compared to nasal delivery [7, 8]. Therefore, we hypothesized that tracheal oxygen supplementation may be able to correct hypoxemia refractory to nasal oxygen supplementation.

This hypothesis was evaluated in a two-phased trial. In a first phase, we evaluated the feasibility of tracheal oxygen supplementation during flexible bronchoscopy and its efficacy to increase the partial pressure of oxygen $\left(\mathrm{PaO}_{2}\right)$ in the arterial blood of healthy volunteers. In a second phase, we evaluated the efficacy of tracheal oxygen delivery to correct a decrease in $\mathrm{SpO}_{2}$ below $90 \%$ during a flexible diagnostic bronchoscopy despite nasal oxygen supplementation.

\section{Materials and Methods}

To achieve a tracheal oxygen administration route, the working channel of the flexible bronchoscope was chosen. For this purpose, a pharyngeal catheter (oxygen probe $\mathrm{CH} 08$, 595.08; Vygon, Ecouen, France) was inserted through the proximal working channel access port of the bronchoscope, after quick clearing of the latter from any obstruction (e.g., secretions). The catheter was then attached to the usual oxygen supply at a prespecified flow rate such that the gas mixture could find its way to the tip of the broncho- scope. All institutional procedural aspects and safety precautions were taken as usually. The local ethical committee approved the studies, and all healthy volunteers and patients signed an informed consent form. The studies were listed on clinicaltrials.gov as NCT01963377 for the first phase and NCT01786642 for the second one.

\section{First Phase}

We recruited 8 healthy volunteers (absence of any current respiratory disease and normal lung function) at our endoscopy department. They all agreed to undergo a flexible bronchoscopy, with local anesthesia using lidocaine. We performed the bronchoscopy while continuously monitoring $\mathrm{SpO}_{2}$ and heart rate using a pulse oximeter. All subjects were wearing a nasal cannula during the whole procedure. Bronchoscopy was performed using 6 different stages in each patient: during ambient breathing, using oxygen supplementation at a flow rate of 2 liters/min and at a flow rate of 4 liters/min. The route of administration was randomly chosen between nasal cannula and tracheal administration. Between the two administration routes, we performed 5 min of room air breathing as a washout period. Capillary partial pressure of oxygen $\left(\mathrm{PCO}_{2}\right)$ and capillary partial pressure of carbon dioxide $\left(\mathrm{PcCO}_{2}\right)$ were measured at the ear lobe at the end of each phase, allowing a steady state after 2 min of oxygen supplementation. The route of administration was blinded to the volunteers by the delivery of ambient air through the alternative channel from which no oxygen was supplied. Throughout the entire procedure, the bronchoscope was maintained in the mid-tracheal position.

\section{Second Phase}

We recruited patients presenting to our endoscopy department for diagnostic bronchoscopy. Patients referred for bronchoalveolar lavage or bronchoscopic aspiration of mucoid impaction were excluded from the study. Patients were not intentionally matched as they were appointed to a subgroup according to their own preference: the lidocaine group (L-group) was subjected to bronchoscopy under local anesthesia alone using topical lidocaine $1 \%$, and the sedated subgroup (S-group) was subjected to bronchoscopy under conscious sedation using an intravenous bolus administration of midazolam $(0.05 \mathrm{mg} / \mathrm{kg})$. At the start of the bronchoscopy, oxygen supplementation was applied using a nasal cannula for every patient in order to maintain or reach a $\mathrm{SpO}_{2}$ above $90 \%$. The patients were monitored by pulse oximetry.

Whenever a desaturation below $90 \%$ occurred during bronchoscopy, the monitoring gear was checked to insure correct signal, and a chin lift and jaw trust maneuver was performed to exclude upper airway collapse as the leading cause of desaturation. When a genuine and irreversible $\mathrm{SpO}_{2}$ below $90 \%$ was affirmed, oxygen supplementation was switched from the nasal cannula to the working channel of the bronchoscope (as described in the first phase), and this without changing the oxygen flow rate. The endoscopic procedure was then temporarily aborted and the position of the tip of the bronchoscope was brought to and maintained in the mid-tracheal position until recovery of $\mathrm{SpO}_{2}$ above $90 \%$. Time to hypoxemia correction was measured, while oxygen flow was kept at a constant rate. Only in case that $\mathrm{SpO}_{2}$ remained below $90 \%$ after 2 min of tracheal oxygen administration, the flow rate was increased by 2 liters/min, and the total time required for correction was measured. 
Fig. 1. Results of oxygen and carbon dioxide values during the six stages of phase I.

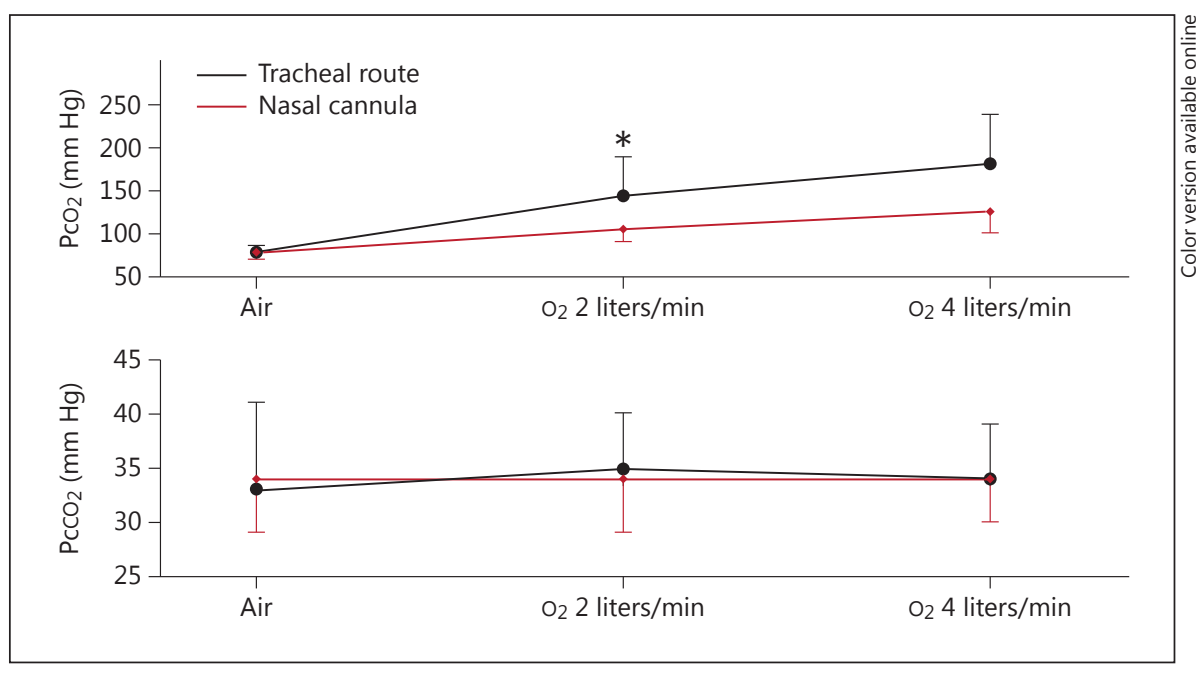

Statistical Analysis

No power analysis was performed for the second phase of the study. The purpose was to observe the effects of tracheal supplementation of oxygen and, without any previous data in the field, the intent was to recruit 40 patients showing desaturation despite oxygen supplementation using nasal cannula, including 20 belonging to the L-group and 20 to the S-group. The statistical analysis was performed using repeated measure ANOVA for the first study phase and Pearson R for the correlation analysis in the second study phase. Interquartile ranges were listed for the data that were not normally distributed.

\section{Results}

\section{First Phase}

Figure 1 shows the results of $\mathrm{PcO}_{2}$ and $\mathrm{PcCO}_{2}$ measurements in each of the six stages of the study protocol. When compared to nasal oxygen delivery, tracheal oxygen delivery leads to significantly higher $\mathrm{PcO}_{2}$ values $(\mathrm{p}<0.001)$. $\mathrm{PCO}_{2}$ values measured during tracheal delivery of air, oxygen at 2 and 4 liters/min were $78 \pm 9,145 \pm 45$ and $181 \pm$ $58 \mathrm{~mm} \mathrm{Hg}$, respectively. The corresponding values for nasal cannula delivery were $78 \pm 8,105 \pm 15$ and $125 \pm 24 \mathrm{~mm}$ $\mathrm{Hg}$. There was no significant change in $\mathrm{PCCO}_{2}$ associated with the oxygen delivery method, and the values in the six stages varied only between 33 and $35 \mathrm{~mm} \mathrm{Hg}$ (fig. 1). There were also no differences in $\mathrm{PCO}_{2}$ when ambient air was delivered through the working channel of the bronchoscope as compared to delivery through a nasal cannula.

\section{Second Phase}

During a 14-month period, one bronchoscopist performed a diagnostic flexible bronchoscopy in 950 patients of whom $30(3.2 \%)$ without exclusion criteria experienced a decrease in $\mathrm{SpO}_{2}$ below 90\% during the flexible bronchoscopy. These 30 patients were considered the study population. The prevalence of desaturation was $2.8 \%(10 / 382)$ for the L-group and 3.4\% (20/568) for the S-group and was not statistically different $(\mathrm{p}=0.57)$.

Table 1 shows the baseline demographics of the study population. The mean $\mathrm{SpO}_{2}$ at the start of the flexible bronchoscopy procedure was $94 \%$ (95\% CI 93-95\%) using a median nasal oxygen flow rate of 2 liters $/ \mathrm{min}$.

Table 2 shows the efficacy of tracheal oxygen administration to correct their decrease in $\mathrm{SpO}_{2}$ below $90 \%$ during flexible bronchoscopy. The lowest $\mathrm{SpO}_{2}$ during bronchoscopy was $76 \%$. Tracheal oxygen supplementation was able to correct $\mathrm{SpO}_{2}$ to a level above $90 \%$ within $120 \mathrm{~s}$ in 22 out of 30 cases (73\%). The $\mathrm{SpO}_{2}$ of the remaining $27 \%$ could also be corrected above $90 \%$, after increasing the oxygen flow to 4 liters $/ \mathrm{min}$. Two thirds of the patients reached $\mathrm{SpO}_{2}$ above $90 \%$ in less than $90 \mathrm{~s}$. The time to reach $\mathrm{SpO}_{2}$ above $90 \%$ was significantly correlated with starting $\mathrm{SpO}_{2}(\mathrm{r}=-0.44 ; \mathrm{p}=0.01)$ and lowest $\mathrm{SpO}_{2}$ during bronchoscopy $(\mathrm{r}=-0.54 ; \mathrm{p}=0.002)$, while no correlation was found with the dose of midazolam and drop in $\mathrm{SpO}_{2}$. In 25 (83\%) patients, the bronchoscopic procedure could be completed as planned after tracheal oxygen administration corrected $\mathrm{SpO}_{2}$ to a level above $90 \%$ and oxygen supplementation was switched back to the nasal route. In $5(17 \%)$ patients, there was recurrent desaturation below a $\mathrm{SpO}_{2}$ value of $90 \%$ when oxygen supplementation was switched back to the nasal route such that the bronchoscopic procedure was terminated.
Yserbyt/De Maeyer/Dooms/Testelmans/ Muylle/Bruyneel/Ninane 
Table 1. Baseline demographics of the patients treated in the second study phase

\begin{tabular}{llll}
\hline & L-group & S-group & Combined \\
\hline $\begin{array}{l}\text { Number of patients } \\
\text { Age, years }\end{array}$ & 10 & 20 & 30 \\
$\begin{array}{l}\text { Male/female } \\
\text { Mean starting SpO } 2\end{array}$ & $7 / 3(66-78)$ & $64(58-72)$ & $67(73-91)$ \\
$\quad$ & & $14 / 6$ & $21 / 9$ \\
$\quad$ 95\% CI), \% & $93(92-95)$ & $94(93-95)$ & $94(93-95)$ \\
$\begin{array}{l}\text { Midazolam dose, mg } \\
\text { Oxygen supplementation }\end{array}$ & $\mathrm{NA}$ & $3(2-3)$ & $\mathrm{NA}$ \\
$\quad$ & $2(2-2)$ & $2(2-2)$ & $2(2-2)$ \\
$\quad$ at start, liters/min & & & \\
Indication for bronchoscopy & & 0 & 1 \\
$\quad$ Asthma & 1 & 5 & 7 \\
$\quad$ Oncology & 1 & 6 & 10 \\
$\quad$ Infection & 2 & 3 & 3 \\
$\quad \begin{array}{l}\text { Transplantation } \\
\text { COPD }\end{array}$ & 4 & 1 & 3 \\
$\quad$ Interstitial lung disease & 2 & 5 & 6 \\
\hline
\end{tabular}

Values are expressed as medians (interquartile ranges) or numbers, unless otherwise indicated. NA = Not applicable; $\mathrm{COPD}=$ chronic obstructive pulmonary disease.

Table 2. Characteristics of desaturation during nasal supplementation and correction during tracheal oxygen supplementation in the second study phase

\begin{tabular}{|c|c|c|c|}
\hline & L-group & S-group & Combined \\
\hline Number of patients & 10 & 20 & 30 \\
\hline Lowest $\mathrm{SpO}_{2}, \%$ & $86(84-88)$ & $86(85-87)$ & $86(85-87)$ \\
\hline Drop in $\mathrm{SpO}_{2}, \%$ & $7(5-9)$ & $9(7-10)$ & $8(7-9)$ \\
\hline Time to reach $\mathrm{SpO}_{2}$ & & & \\
\hline$>90 \%, \mathrm{~s}$ & $78(22-134)$ & $90(53-127)$ & $86(57-115)$ \\
\hline $\mathrm{SpO}_{2}$ at $120 \mathrm{~s}, \%$ & $92(90-94)$ & $92(90-93)$ & $92(91-93)$ \\
\hline $\begin{array}{l}\text { Proportion of patients } \\
\text { reaching } \mathrm{SpO}_{2} \\
>90 \% \text { within } 120 \mathrm{~s}\end{array}$ & $8 / 10$ & $14 / 20$ & $22 / 30$ \\
\hline
\end{tabular}

Values are expressed as means (95\% CI), unless otherwise indicated.

\section{Discussion}

Our two-phased study shows that tracheal oxygen supplementation through the working channel of a bronchoscope is feasible and an efficient method to correct $\mathrm{SpO}_{2}$ below $90 \%$ during flexible bronchoscopy that occurs despite oxygen delivery through nasal cannula using a similar flow rate.

Tracheal Oxygen Supplementation during Flexible Bronchoscopy
Multiple factors contribute to hypoxemia during bronchoscopy [9-13]. The bronchoscope itself reduces the cross-sectional area of the airway, leading to airflow limitation. When the bronchoscope is directed towards more narrow parts of the bronchial tree, the bronchoscope will almost entirely fill the bronchus, thus creating a ventilation-perfusion mismatch. In addition, sedative drugs could theoretically lead to hypoventilation and/or upper airway obstruction. Nasal oxygen supplementation has become the standard method to avoid desaturation during flexible bronchoscopy [5]. Alternative methods are the use of noninvasive mask ventilation in critically ill patients requiring bronchoscopy, the use of high-flow nasal cannula oxygenation or a nasopharyngeal tube [14-17].

Nasal oxygen supplementation works by increasing the nasal and pharyngeal partial pressure of oxygen $\left(\mathrm{pO}_{2}\right)$. Although it will lead to higher alveolar $\mathrm{pO}_{2}$, the results obtained in the present study clearly demonstrate that it is less efficient than direct tracheal administration. Previous studies have shown the considerable variability of inspired oxygen concentration both within and between subjects breathing via nasal cannula, confirming the unpredictable performance of these devices and factors associated with this variability include, among others, mouth breathing and peak inspiratory flow that seem difficult to control during bronchoscopy [18-20]. It is also likely that the airflow limitation and ventilation-perfusion mismatch caused by the bronchoscope still play a role. When supplementing the oxygen directly through the bronchoscope, these shortcomings are partially bypassed.

Our feasibility study demonstrates that tracheal oxygen administration will lead to significant higher $\mathrm{PCO}_{2}$ values in healthy volunteers, regardless of the flow rate. At the same time, $\mathrm{PcCO}_{2}$ levels remained unchanged. The oxygen supplementation technique also appeared to be feasible and safe. In the second phase of our study, we used these data to design a trial to demonstrate that tracheal oxygen supplementation is able to correct hypoxemia occurring despite nasal oxygen supplementation. $\mathrm{SpO}_{2}$ was corrected above $90 \%$ within 120 s in $22 / 30$ (73\%) patients. In the remaining $27 \%$ of the patients, $\mathrm{SpO}_{2}$ could ultimately also be corrected after increasing the oxygen flow rate to 4 liters/min. Our intervention also allowed resuming and completing the bronchoscopic intervention in $83 \%$ of the study population.

The present study has limitations. The L-group, based on local anesthesia only, included 10 patients instead of the 20 who were preplanned. This is explained by the fact that, in the meantime, sedation has become the reference for bronchoscopic procedure in our hospital such that re- 
cruitment in the 'local anesthesia' group has become more and more difficult. However, we believe that this is unlikely to affect the results since the sedation group included 20 patients who were more likely to experience severe desaturation, and tracheal oxygen delivery was efficient in this subgroup. Arterialized earlobe $\mathrm{PcO}_{2}$ samples were used in the first phase of the study to limit invasiveness. There are, however, differences between $\mathrm{PcO}_{2}$ and $\mathrm{PaO}_{2}$, but we believe that this is unlikely to be important since the purpose was mainly to assess differences in partial pressures between conditions (e.g., different oxygen flow rates), and these differences are probably not affected by these different methods [21]. Finally, patients who were planned for a bronchoscopic procedure requiring prolonged use of the working channel (mucoid impaction, bronchoalveolar lavage and bleeding) were excluded to avoid competition between the bronchoscopic procedure and tracheal delivery of oxygen. As a consequence, this methodology comprises an important limitation to our work because patients with endobronchial impaction or bleeding are especially at risk for periprocedural hypoxemia. Ideally, a bronchoscope with a working channel and an oxygen supplementation channel would have to be designed to avoid this competition. This was, however, beyond the scope of our feasibility study. Further studies are required in these patients, but the very rapid correction of desaturation associated with tracheal delivery of oxygen suggests that this technique is also feasible in that particular population.

In conclusion, we can state that tracheal oxygen supplementation using the working channel of a bronchoscope seems safe, feasible and an effective and simple way to restore oxygen saturation levels during flexible bronchoscopy, allowing the endoscopist to rapidly resume the examination in most cases. We believe it is justified to perform a randomized trial, comparing increasing the nasal oxygen flow to switching to tracheal oxygen administration. This trial should point out, which route is most effective.

\section{Disclosure Statement}

None of the authors have competing interests to disclose.

\section{References}

1 Milman N, Faurschou P, Grode G, Jørgensen A: Pulse oxymetry during fibreoptic bronchoscopy in local anaesthesia: frequency of hypoxaemia and effect of oxygen supplementation. Respiration 1994;61:342-347.

2 Stolz D, Chhajed PN, Leuppi JD, Brutsche M, Pflimlin E, Tamm M: Cough suppression during flexible bronchoscopy using combined sedation with midazolam and hydrocodone: a randomised, double blind, placebo controlled trial. Thorax 2004;59:773-776.

-3 Schlatter L, Pflimlin E, Fehrke B, Meyer A, Tamm M, Stolz D: Propofol versus propofol plus hydrocodone for flexible bronchoscopy: a randomised study. Eur Respir J 2011;38: 529-537.

4 Shrader DL, Lakshminarayan S: The effect of fiberoptic bronchoscopy on cardiac rhythm. Chest 1978;73:821-824.

5 Du Rand IA, Blaikley J, Booton R, et al: British thoracic society guideline for diagnostic flexible bronchoscopy in adults. Thorax 2013; 68:i1-i44.

6 O'Reilly Nugent A, Kelly PT, Stanton J, Swanney MP, Graham B, Beckert L: Measurement of oxygen concentration delivered via nasal cannulae by tracheal sampling. Respirology 2014; 19:538-543.

7 Christopher KL, et al: Transtracheal oxygen therapy. Chest 2011;139:435-440.
8 Kampelmacher MJ, Deenstra M, van Kesteren RG, Melissant CF, Douze JMC, Lammers J-WJ: Transtracheal oxygen therapy: an effective and safe alternative to nasal oxygen administration. Eur Respir J 1997;10:828833.

-9 Editorial: safety and fibreoptic bronchoscopy. Br Med J 1974;3:542-543.

10 Dubrowsky C, Awe RJ, Jenkins DE: The effect of bronchofiberscopic examination on oxygenation status. Chest 1975;67:137-140.

11 Albertini RE, Harrell JH, Moser KM: Management of arterial hypoxemia induced by fiberoptic bronchoscopy. Chest 1975;67:134136.

12 Katz VS, Michelson EL, Stawicki J, Holford FD: Cardiac arrythmias, frequency during fiberoptic bronchoscopy and correlation with hypoxemia. Ann Intern Med 1981;141:603606.

13 Salisbury BG, Metzger LF, Altose MD, Stanley NN, Cherniak NS: Effect of fiberoptic bronchoscopy on respiratory performance in patients with chronic airways obstruction. Tho$\operatorname{rax} 1975 ; 30: 441-446$

14 Simon M, Braune S, Frings D, Wiontzek AK, Klose H, Kluge S: High-flow nasal cannula oxygen versus non-invasive ventilation in patients with acute hypoxaemic respiratory failure undergoing flexible bronchoscopy - a prospective randomised trial. Crit Care 2014; 18:712.
15 Diab S, Fraser JF: Maintaining oxygenation successfully with high flow nasal cannula during diagnostic bronchoscopy on a postoperative lung transplant patient in the intensive care. Case Rep Crit Care 2014;2014:198262.

-16 Lucangelo U, Vassallo FG, Marras E, Ferluga M, Beziza E, Comuzzi L, Berlot G, Zin WA: High-flow nasal interface improves oxygenation in patients undergoing bronchoscopy. Crit Care Res Pract 2012;2012:506382.

$\checkmark 17$ Chhajed PN, Aboyoun C, Malouf MA, Hopkins PM, Plit M, Grunstein RR, Glanville AR: Management of acute hypoxemia during flexible bronchoscopy with insertion of a nasopharyngeal tube in lung transplant recipients. Chest 2002;121:1350-1354.

18 Henderson CL, Rosen HD, Arney KL: Oxygen flow through nasal cannulae. Can J Anaesth 1996;43:636-639.

19 Bazuaye EA, Stone TN, Corris PA, Gibson GJ: Variability of inspired oxygen concentration with nasal cannulas. Thorax 1992;47:609611.

20 Bethune DW, Collis JM: An evaluation of oxygen therapy equipment. Experimental study of various devices on the human subject. Tho$\operatorname{rax} 1967 ; 22: 221-225$.

21 Sauty A, Uldry C, Debétaz LF, Leuenberger P, Fitting JW: Differences in $\mathrm{PO} 2$ and $\mathrm{PCO} 2$ between arterial and arterialized earlobe samples. Eur Respir J 1996;9:186-189. 